\title{
Geomatics-Based Framework for Assessing Environmental Impacts of Grand Ethiopian Renaissance Dam (GERD) Reservoir
}

\author{
Mahmoud A. Hassaan \\ Institute of Graduate Studies and Research, Alexandria University, Alexandria, Egypt \\ Email:mhassaan@alexu.edu.eg
}

How to cite this paper: Hassaan, M. A. (2021). Geomatics-Based Framework for Assessing Environmental Impacts of Grand Ethiopian Renaissance Dam (GERD) Reservoir. Journal of Geoscience and Environment Protection, 9, 72-83.

https://doi.org/10.4236/gep.2021.912005

Received: November 5, 2021

Accepted: December 14, 2021

Published: December 17, 2021

Copyright $\odot 2021$ by author(s) and Scientific Research Publishing Inc. This work is licensed under the Creative Commons Attribution International License (CC BY 4.0).

http://creativecommons.org/licenses/by/4.0/

\begin{abstract}
Despite the benefits of big project dams, their reservoirs may have significant environmental impacts. The main objective of this paper is to develop an integrated analysis framework of remotely-sensed data ad GIS techniques for delineating surface area of the dam reservoir, simulating their capacities and assessing associated environmental impacts with application to Grand Ethiopian Renaissance Dam (GERD). For this purpose, a methodology of four main steps was applied. The methodology involved delineating the up-to-date reservoir using remotely sensed data, simulating reservoir at full capacity, estimating current and potential reservoir capacity and finally assessing environmental impacts of the reservoir. The results revealed that the up-to-date reservoir covers a total area of $330.3 \mathrm{~km}^{2}$ with a gross storage capacity of 12 billion $\mathrm{m}^{3}$. Under full capacity scenario, the reservoir is estimated to cover a total area of $1650.9 \mathrm{~km}^{2}$, with a storage capacity of 63.4 billion $\mathrm{m}^{3}$. The GERD reservoir may lead to dramatic changes in the local environment with significant implications at both regional and global scales. In this respect, it was found that the reservoir will lead to destruction of ecosystems in a total area of $1300 \mathrm{~km}^{2}$ covered by grasslands and Savannah. Also, the GERD reservoir is expected to have significant impacts on GHGs emissions and global warming. Moreover, a massive quantity of water is expected to be lost by surface evaporation.
\end{abstract}

\section{Keywords}

Remote Sensing, GIS, Dams’ Reservoirs, GERD

\section{Introduction}

Big dam projects have usually a variety of benefits in terms of securing water 
supply, supporting irrigated agriculture, controlling the flood, and generating reliable hydroelectric power. However, dams and associated reservoirs lead usually to dramatic changes in the local site of the dam and beyond that have significant direct and indirect environmental impacts along with economic and cultural losses. These impacts may involve population resettlement, inundation of faunal and flora, changing in natural landscape, distracting archaeological and historical features, deteriorating water quality, changing in the hydrological regime and altering micro-climate (Wang et al., 2012; Devic, 2015; Abtew \& Dessu, 2019). Knowledge of the surface area and storage capacities of dams' reservoirs is essential not only for planning and managing water resources but also for assessing impacts of these reservoirs in advance. In this context, remote sensing and GIS techniques can assist in simulating dam reservoirs, delineating their surface area, simulating their storage capacities and assessing associated impacts.

Remotely sensed data provide synoptic, real-time, dynamic and cost-effective information. Therefore, they are commonly used in delineating and monitoring surface area of water bodies (Du et al., 2016), particularly in the case of lack of data, inaccessible areas and insufficient financial resources required for conventional in situ measurements (Hassaan, 2009). Generally, water bodies have distinguished spectral behavior, which is characterized by noticeable low reflectance in Near-infrared (NIR) and Mid-infrared (MIR) regions of the spectrum compared to visible wavelengths. In contrast, the reflectance of various land covers in NIR and MIR is relatively higher compared to visible wavelengths.

Based on this notion, a wide range of methods were suggested to extract water bodies from remotely sensed data. These methods include, for example, band slicing or histogram thresholding, band rationing, classification and spectral indices (Hassaan, 2012; Du et al., 2016). For example, classification and visual interpretation were applied to delineate surface areas of water reservoirs that were utilized in combination with ground truth data on water depth in these reservoirs to develop volume-area relationships and estimate their storage capacities (Sawunyama et al., 2006; Rodrigues et al., 2012).

Among these methods, Normalized Difference Water Index (NDWI) is commonly employed as a more reliable, user-friendly and efficient method with low computational cost (Du et al., 2016). Generally, NDWI ensures maximizing the reflectance of the water body in the short visible wavelengths (blue and green) and minimizing the reflectance of water body in the NIR wavelengths (Du et al., 2016).

Starting from the mid-1990s, varied forms of NDWI were suggested proposed in the past few decades. These different forms are applied to extract water bodies in Landsat MSS, TM, ETM+ and OLI imageries (McFeeters, 1996; Xu, 2006; Xu, 2007; Du et al., 2014; Sarp \& Ozcelik, 2017). More recently, Sentinel-2 imageries provided information in fine spectral, spatial and temporal resolutions. Senti- 
nel-2 satellites acquire radiometric information through 13 spectral bands: four bands at $10 \mathrm{~m}$, six bands at $20 \mathrm{~m}$ and three bands at $60 \mathrm{~m}$ spatial resolution. The revisit frequency of every single Sentinel-2 satellite is 10 days (Chen et al., 2018; Lupia et al., 2018). Having such improved spectral, spatial and temporal resolutions, Sentinel-2 imageries can be effectively used in mapping and monitoring water bodies ( $\mathrm{Du}$ et al., 2016).

Also, remote sensing techniques provide satellite imagery-based Digital Elevation Models (DEMs) including, for example, ASTER (Advanced Spaceborne Thermal Emission and Reflection Radiometer) and SRTM (Shuttle Radar Topography Mission) (Bhakar et al., 2010). Such satellite imagery-based DEMs provide detailed synoptic elevation information. Accordingly, they were used, through GIS, in simulating dams' reservoirs and developing Area-Volume-Elevation (AVE) relationship (İRVEM, 2011; Sayl et al., 2017).

It should be noted that major proportions of the previous research work on simulating water reservoirs were based partially on ground truth data and conventional data sources that are costly and time-consuming tasks [e.g. (Sawunyama et al., 2006; Rodrigues et al., 2012)]. Also, some of previous research work applied GIS to develop AVE relationship and estimate the reservoirs storage capacity through conventional DEM interpolated from topographic maps (İRVEM, 2011) or satellite imagery-based DEM (Ahmed et al., 2016; Sayl et al., 2017). Accordingly, none of previous research work, up to our knowledge, employed GIS, multispectral satellite images and satellite imagery-based DEM in simulating Dams' reservoirs.

This paper is intended to develop an integrated analysis framework of remotely-sensed data and GIS techniques for delineating surface area of the dam reservoir, simulating their capacities and assessing associated impacts environmental impacts with application to Grand Ethiopian Renaissance Dam (GERD).

\section{Grand Ethiopian Renaissance Dam (GERD)}

In 2011, Ethiopia began to construct the Grand Ethiopian Renaissance Dam (GERD) along the Blue Nile River (Figure 1), which is the largest tributary of the Nile River contributing about $60 \%$ of the annual water budget of the flows received at Aswan Dam (EL Bastawesy, 2015). GERD is expected to be the largest hydroelectric power generation facility in Africa and the fifth largest in the world (Wheeler et al., 2020). GERD is planned to generate 5.1 - 6.4 gigawatts of energy providing power to sixty-five million Ethiopians who currently lack access to regular power (Booth, 2020). The minimum operating level of the reservoir water is planned to be $640 \mathrm{~m}$ above mean sea level (Mulat \& Moges, 2014).

Regionally, the estimation of maximum storage capacity for GERD is of particular concern to downstream countries: Sudan and Egypt, due to its expected impacts on their water supplies (EL Bastawesy, 2015). Filling the reservoir during 


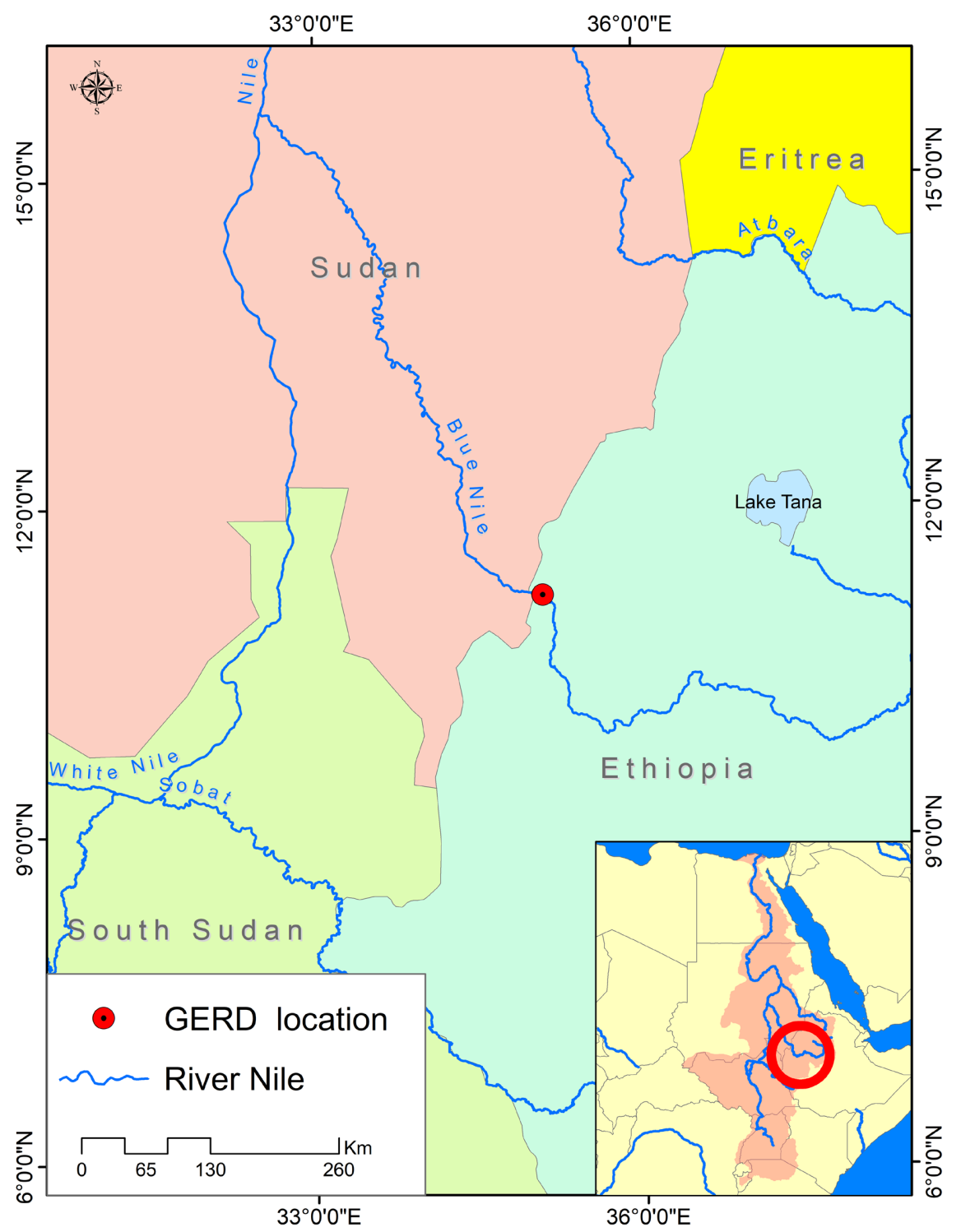

Figure 1. Situation of GERD.

a short period and during a low flood seasons will considerably reduce the annual downstream discharge and adversely affect downstream countries, particularly Egypt (El Bastawesy et al., 2015; El-Nashar \& Elyamany, 2018). For instance, it was estimated that under the scenario of a 6-years filling period plan, the annual energy output from High Aswan Dam (HAD) is expected to decrease by 7 - 12 (Mulat \& Moges, 2014). Moreover, GERD reservoir may lead to dramatic changes in the local environment with significant global and regional implications.

\section{Data and Methodology}

For the sake of the research paper in hand, an analysis framework of four main steps (Figure 2) was suggested as follows:

Step I: Delineating up-to-date reservoir. 


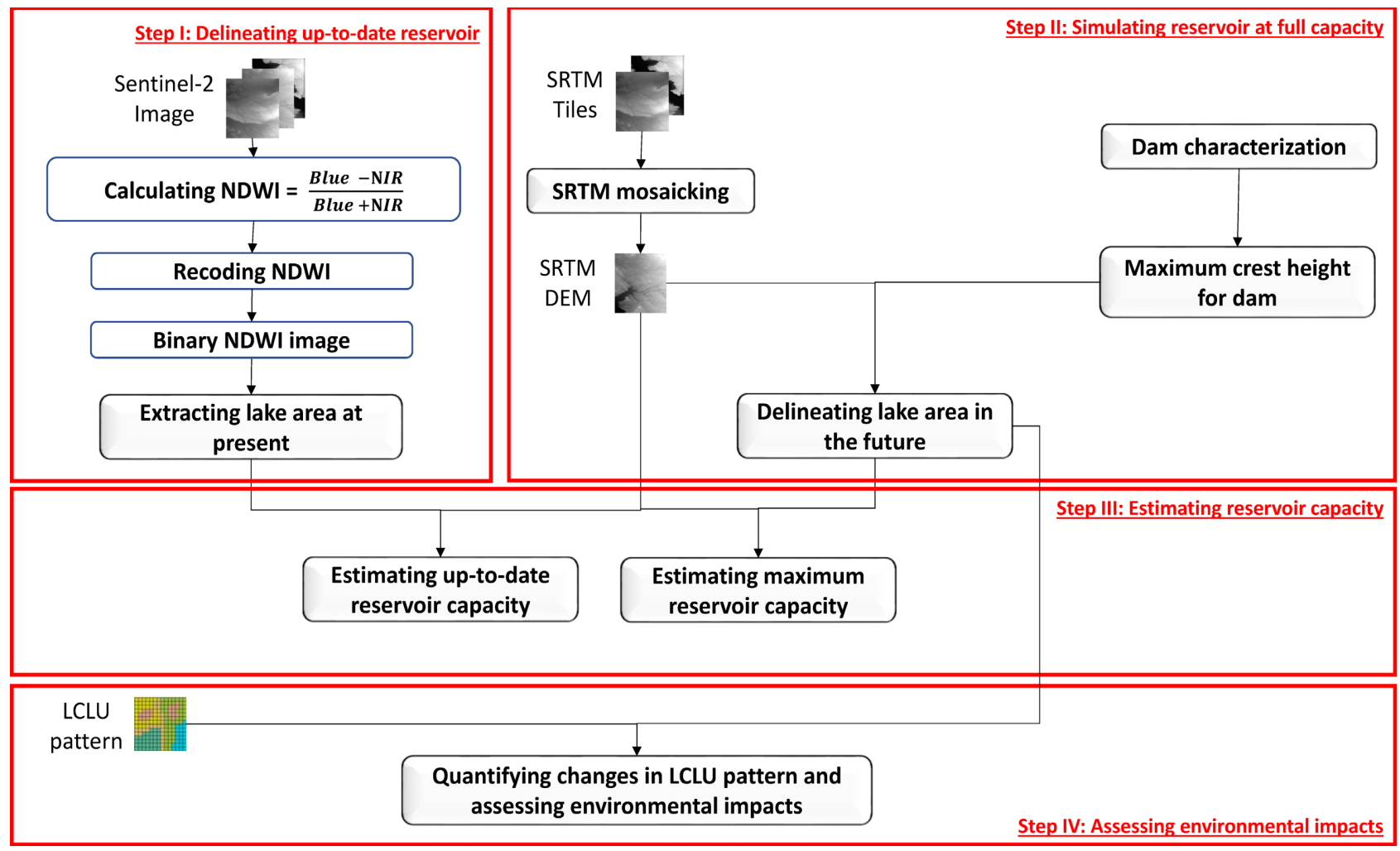

Figure 2. Methodology for simulating and assessing environmental impacts of GERD reservoir through remote sensing and GIS techniques.

To delineate up-to-date reservoir, two Sentinel-2 image dated 10/03/2021 and 26/10/2021 were downloaded from Copernicus Open Access Hub (ESA, 2021). The surface area of GERD reservoir from in the two points of time was delineated from Sentinel-2 images through Normalized Difference Water Index (NDWI) according to the following formula:

$$
\text { NDWI }=\frac{\text { Blue }- \text { NIR }}{\text { Blue }+ \text { NIR }}
$$

(Du et al., 2016).

It should be noted that the fine spatial resolution of both blue and NIR bands (10 meters) ensures that the resulted index image reveals water bodies with subtle spatial details and smoother boundaries.

Step II: Simulating reservoir at full capacity.

Based on the planned minimum operating level of the reservoir water, which was estimated to be $640 \mathrm{~m}$ above mean sea level (Mulat \& Moges, 2014) and the local topography, the maximum crest height of GERD, the reservoir under full capacity scenario was identified. For this purpose, Shuttle Radar Topography Mission (SRTM) DEM were downloaded from Earth Explorer (USGS, 2020), which is a Web application that enables users to find, preview, and download digital data published by the U.S. Geological Survey. Earth Explorer provides free worldwide coverage of satellite imagery-based DEM at a resolution of 1 arc-second (30 meters) (USGS, 2020). Four tiles of SRTM DEM (each 1-degree 
dimension) were downloaded and mosaicked to generate a DEM for the complete area of GERD site and its surroundings. Thereafter, the DEM was utilized in delineating the surface area of the reservoir under full capacity scenario through Spatial Analyst tools (ArcGIS V. 10.8).

Step III: Estimating reservoir capacity.

The extracted surface area of up-to-date reservoir and estimated one under full capacity scenarios were used for masking DEM. Thereafter, the masked DEMs were employed in developing Area-Volume-Elevation (AVE) curve. Accordingly, the reservoir capacity at both cases were estimated through Spatial Analyst tools (ArcGIS V. 10.8).

Step IV: Assessing environmental impacts.

Finally, the environmental impacts of GERD and associated reservoir were assessed. For this purpose, data on global land cover in 2019 were downloaded from MCD12C1 MODIS, which provides data on global land cover at 0.05 degree (5600 meter) spatial resolution for the entire globe from 2001 to 2019 (Friedl \& Sulla-Menashe, 2015). The downloaded land cover and reservoir under full capacity scenario were overlaid to profile and quantify various impacts of the reservoir.

\section{Results and Discussion}

Based on the surface area of GERD reservoir delineated from Sentinel-2 image dated 10/03/2021, the reservoir had a total area of $182.3 \mathrm{~km}^{2}$. The reservoir water surface was found to have an elevation of $565 \mathrm{~m}$ above mean sea level with gross storage capacity of 6.4 billion $\mathrm{m}^{3}$ (Table 1). Meanwhile, surface area of the most recent GERD reservoir, delineated from Sentinel-2 image dated $26 / 10 / 2021$, covers a total area of $330.3 \mathrm{~km}^{2}$ with a gross storage capacity of 12 billion $\mathrm{m}^{3}$.

Under full capacity scenario, it is expected that the maximum crest height of GERD is estimated to be at $640 \mathrm{~m}$ above mean sea level. Accordingly, the reservoir is estimated to cover a total area of $1650.9 \mathrm{~km}^{2}$ (Figure 3), with maximum storage capacity of 63.4 billion $\mathrm{m}^{3}$.

To estimate surface area, storage capacity and depth of reservoir at different elevations, the area-volume-elevation (AVE) curve of the reservoir is usually employed (Sayl et al., 2017). Based on area-volume-elevation (AVE) curve that was developed to visualize the relationships between elevation, surface area and capacity of GERD reservoir (Figure 4). Generally, it was found that the maximum

Table 1. Development of surface area and capacity of GERD reservoir.

\begin{tabular}{ccc}
\hline Date & Surface area $\left(\mathrm{km}^{2}\right)$ & Reservoir capacity $\left(\right.$ billion $\left.\mathrm{m}^{3}\right)$ \\
\hline $10 / 03 / 2021$ & 182.3 & 6.4 \\
$26 / 10 / 2021$ & 330.3 & 12.0 \\
Future full capacity scenario & 1650.9 & 63.4 \\
\hline
\end{tabular}




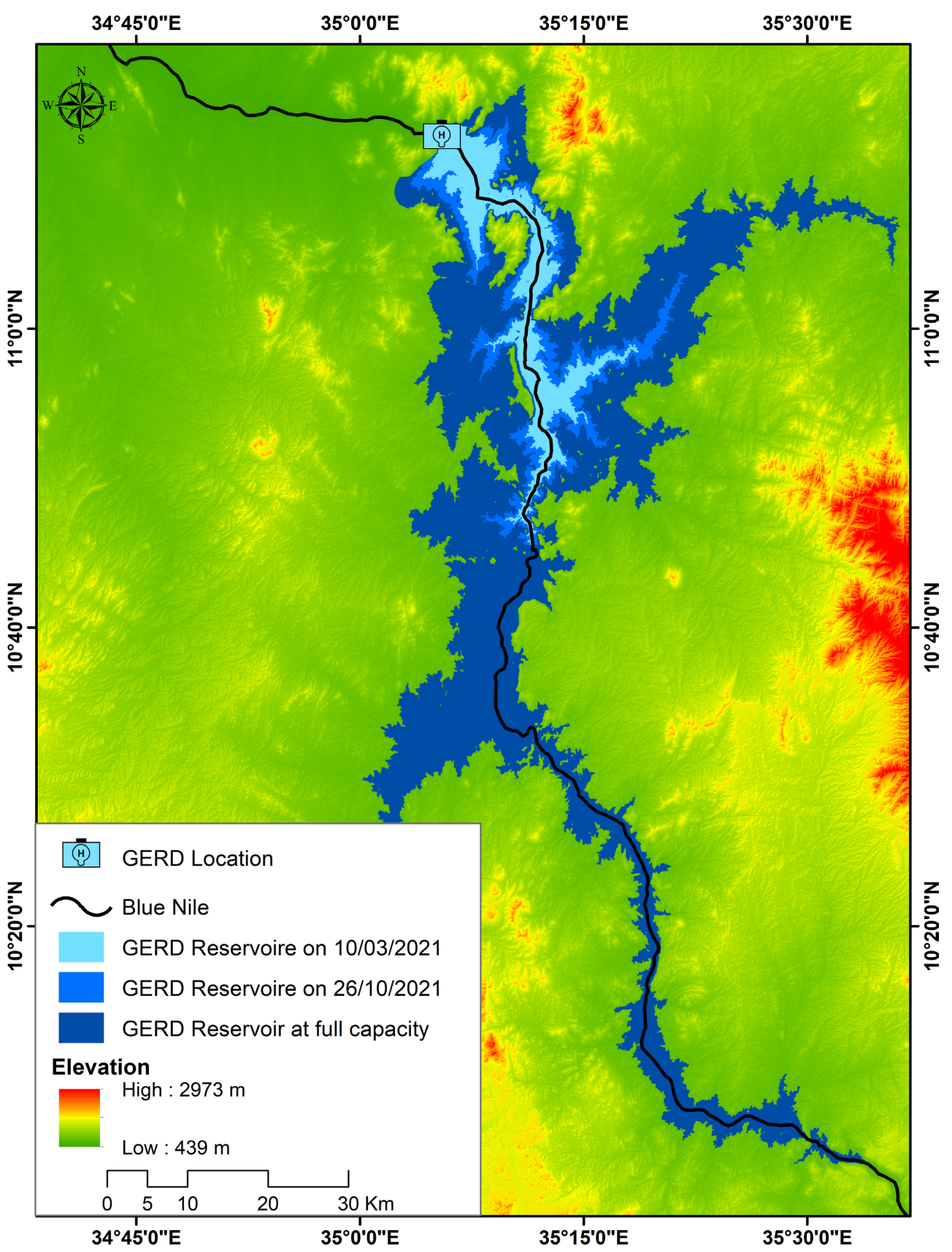

Figure 3. Current and potential GERD reservoir.

depth of GERD reservoir under full capacity scenario is estimated to be $130 \mathrm{~m}$. It should be noted that the polynomial form of the relationship between elevation on one hand and both surface area and volume on the other, indicates to increasing slope with height in the site of GERD and its surrounding. Generally, it should be noted that such an estimate is generally consistent with previous estimates (El Bastawesy et al., 2015).

Also, it was noted that $16.17 \%$ of the total area of GERD reservoir area will have a depth less than 10 meter, while $32.65 \%$ of the total reservoir area are expected to have a depth less than 20 meter. Such considerable areas of a relatively 


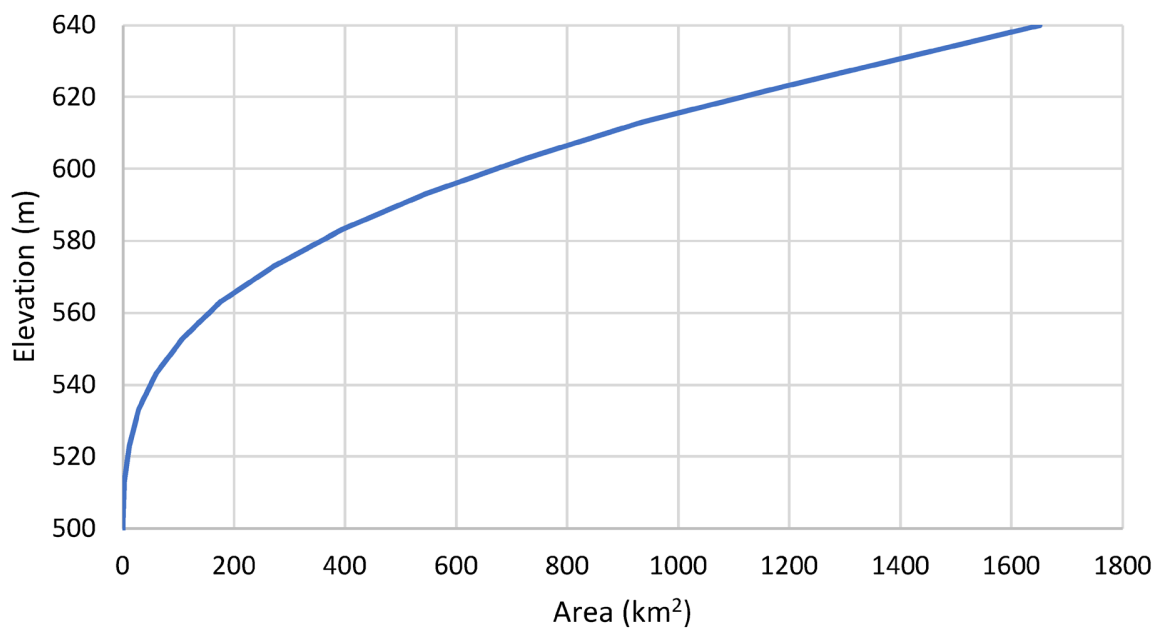

(a)

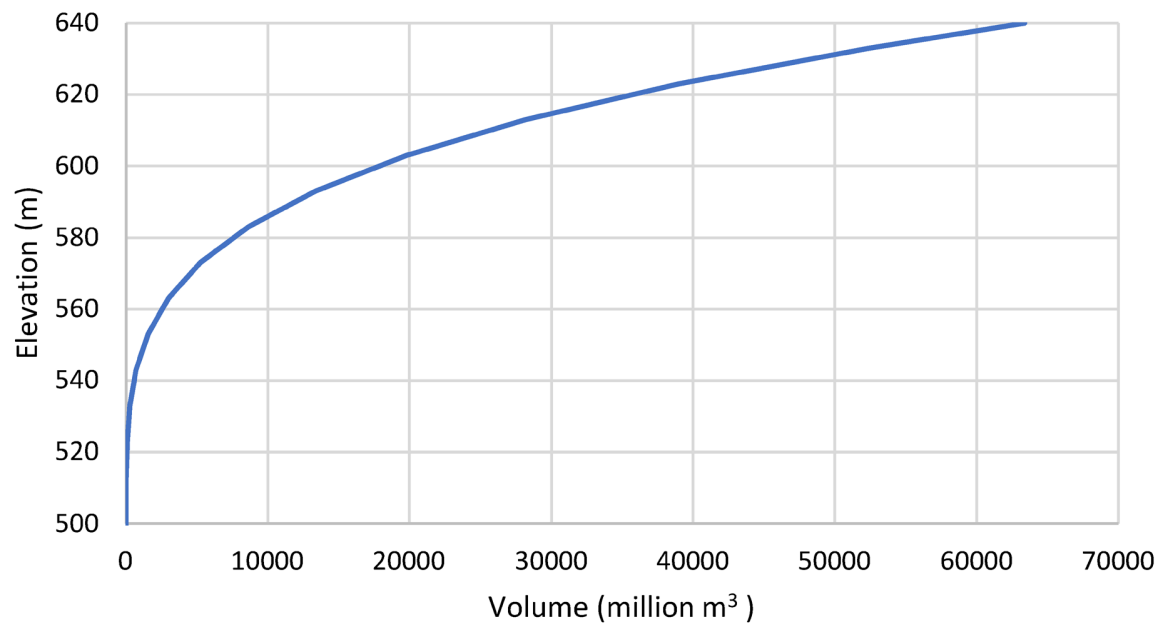

(b)

Figure 4. GERD reservoir Area-Elevation (a) and Volume-Elevation (b) under full capacity scenario.

shallow reservoir area are expected to have significant impacts on reducing the capacity of the reservoir over time due to sedimentation process. Usually, as a result of trapping of sediments and consequent sediment accumulation reduces the storage capacity of the water in a reservoir. Due to sedimentation process, the reservoirs lose some of the storage capacity for which they were initially designed (Phyoe \& Wang, 2019). For instance, it was suggested that $0.5 \%$ to $1 \%$ on average of the storage capacity of reservoirs is lost annually worldwide due sedimentation (Schleiss et al., 2016).

GERD reservoir, under full capacity scenario, is expected to have a wide range of significant environmental impacts at both local and global levels. Figure 5 provides a schematic diagram highlighting the interrelationships between GERD reservoir and its implications. For example, a total area of about $1650.9 \mathrm{~km}^{2}$, upstream of the dam is expected to be inundated. This means destruction of terrestrial natural ecosystems in these inundated areas. GERD reservoir area under full capacity and land cover in the reservoir area and it surrounding were overlaid. 


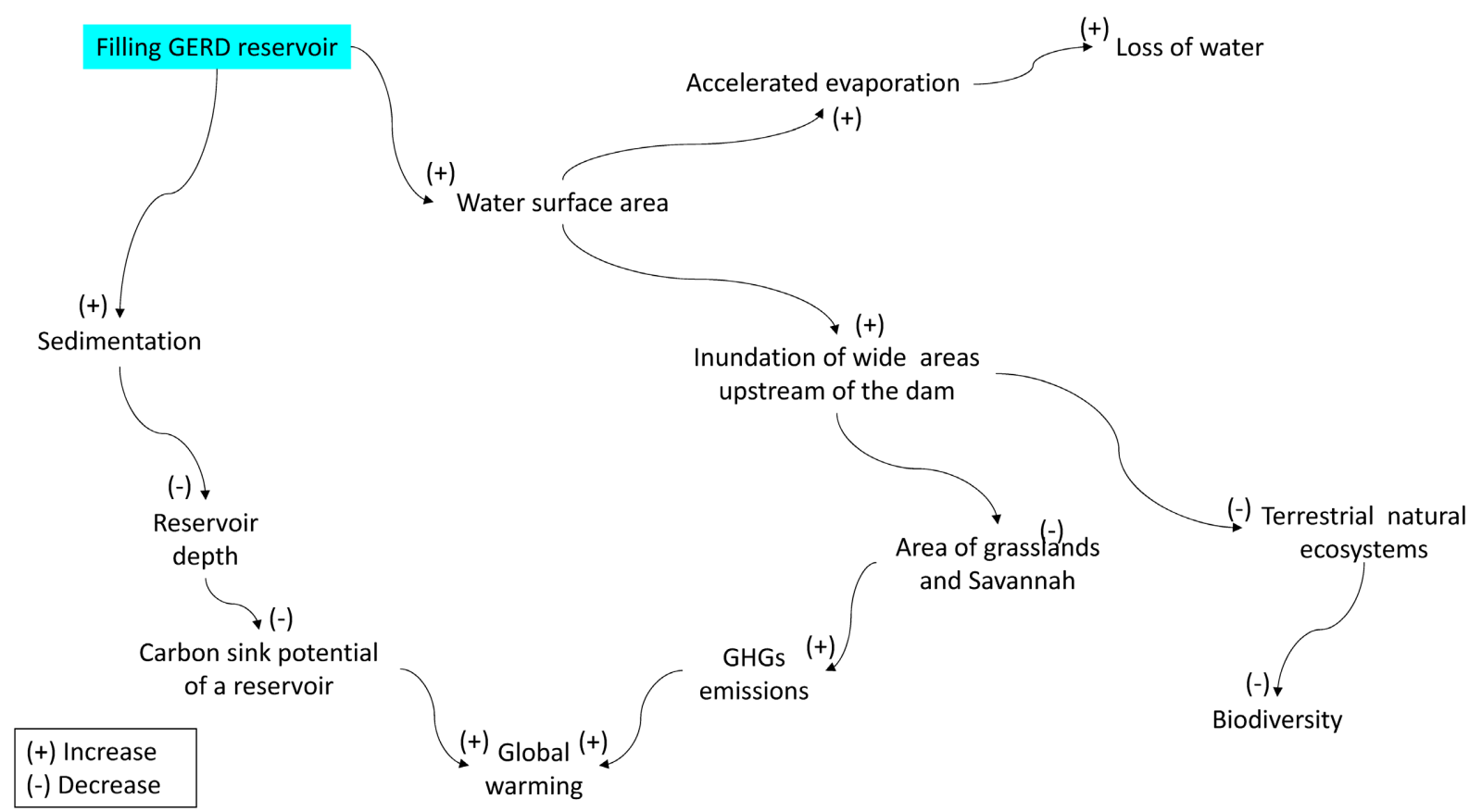

Figure 5. Schematic diagram of potential environmental impacts of GERD reservoir.

The overlay analysis revealed that $20 \%$ of the areas vulnerable to be inundated by the reservoir are currently croplands, $18 \%$ are grasslands and $62 \%$ are Savannah. This implies that the reservoir will lead to vanish large area of grasslands and Savannah exceeding $1300 \mathrm{~km}^{2}$. This, consequently means, destruction of ecosystems in these areas.

It should be noted that such a loss of wide areas of grass lands and Savannah may have significant implications on GHGs emissions and global warming. Usually, vegetation cover in general and grasslands in particular can support mitigating climate change though their carbon sequestration mechanisms and acting as carbon sinks (Soussana et al., 2010; Toochi, 2018). In this respect, the annual average carbon sink potential of grasslands and Savannah was estimated to be 0.14 ton carbon/ha (Grace et al., 2006). Based on such an estimate, it can be argued that the disappearance of about $1300 \mathrm{~km}^{3}$ of grasslands and savannahs as a result of GERD reservoir will lead to increase carbon emissions by 18700 tons year $^{-1}$. Additionally, the impacts of GERD on global warming can be manifested in Hydroelectric power plants and GHGs emissions from GERD reservoir, where the hydro plants with large reservoirs in tropical regions have usually a much greater impact on global warming than fossil fuel plants generating equivalent amounts of electricity (Devic, 2015). Therefore, there is growing concern regarding increasing greenhouse gas emissions due to GERD reservoir.

Generally, the carbon sink potential of a reservoir is determined by a number of factors including for example reservoir depth, and local climate, where shallow reservoirs in hot climates have high levels of GHGs emissions (Devic, 2015). Therefore, it can be argued that, the impacts of GERD reservoirs on GHGs emissions are expected to be exaugurated over time due to continued sedimentation 
processes and subsequent shallow reservoir. This is emphasized by the fact that one-third of GERD reservoir is expected to have a depth of less than 20 meter, the impact of GERD reservoir on global warming can be accelerated over time as a result of cut-off of sediment transport by GERD dam, which leads to sediments trapping and shallowing the reservoir. This means that the issue of GHGs emissions from GERD reservoir is expected to be exaugurated over time due to sedimentation that will lead, in turn, to shallowing the reservoir.

Moreover, GERD reservoir may lead to loss of water due to accelerated evaporation from wide surface area of the reservoir. In this context, the annual evaporation rate in the area of GERD and its surrounding was estimated to be $1189 \mathrm{~mm} /$ year (Khairy et al., 2019). This suggested about 1.9 billion $\mathrm{m}^{3} /$ year on average of water will be lost due to evaporation under full capacity scenario.

\section{Conclusion}

The application of the proposed framework analysis in the case of GERD reservoir revealed that the great potentials of Geomatics not only for simulating dams' reservoirs and monitoring water storage for the dams' reservoirs but also for quantifying their potential environmental impacts. In this context, it was found that GERD reservoir is estimated to cover a total area of $1650.9 \mathrm{~km}^{2}$, with a storage capacity of 63.4 billion $\mathrm{m}^{3}$ under full capacity scenario. Additionally, the proposed framework analysis can assist in quantifying the associated impacts on the environment at both local, regional and global levels. In this respect, it was found that the dramatic changes associated with the GERD reservoir will have significant regional and regional implications. For example, it was estimated that the reservoir will lead to the destruction of ecosystems, accelerated GHGs emissions and loss of water due to surface evaporation. Generally, it can be argued that the proposed analysis framework can play a crucial role not only in supporting successful management of the Nile's water as one of the largest transnational river basins, but also in mitigating various adverse impacts of the reservoir on the environment.

\section{Conflicts of Interest}

The author declares no conflicts of interest regarding the publication of this paper.

\section{References}

Abtew, W., \& Dessu, S. B. (2019). The Grand Ethiopian Renaissance Dam on the Blue Nile. Springer International Publishing. https://doi.org/10.1007/978-3-319-97094-3

Ahmed, E., Nabi, G., Ahsan, M., \& Arshad, A. (2016). Comparison of Satellite Images for Estimation of Reservoir Characteristics Using GIS Based Techniques: A Case Study of Three Dams i.e. Domli, Baral (Lehri) and Chamak Mira in Pakistan. Science International, 28, 441-445.

Bhakar, R., Srivastav, S. K., \& Punia, M. (2010). Assessment of the Relative Accuracy of ASTER and SRTM Digital Elevation Models along Irrigation Channel Banks of Indira Gandhi Canal Project Area, Rajasthan. Journal of Water \& Land-Use Management, 10, $1-11$. 
Booth, C. D. (2020). The Temperature Is Rising, the Fever White Hot: The Grand Ethiopian Renaissance Dam as Flashpoint between Egypt and Ethiopia. Atlantic Council.

Chen, F., Cheng, M., Li, J., Wang, C., \& Claverie, M. (2018). A Comparison of Sentinel -2A and Sentinel-2B with Preliminary Results. In IEEE International Geoscience and Remote Sensing Symposium (IGARSS) (pp. 8226-8229). Institute of Electrical and Electronics Engineers. https://ieeexplore.ieee.org/xpl/conhome/8496405/proceeding

Devic, G. (2015). Environmental Impacts of Reservoirs. In R. H. Armon, \& O. Hänninen (Eds.), Environmental Indicators (pp. 561-575). Springer.

Du, Y., Zhang, Y., Ling, F., Wang, Q., Li, W., \& Li, X. (2016). Water Bodies' Mapping from Sentinel-2 Imagery with Modified Normalized Difference Water Index at 10-m Spatial Resolution Produced by Sharpening the SWIR Band. Remote Sensing, 8, Article No. 354. https://doi.org/10.3390/rs8040354

Du, Z., Li, W., Zhou, D., Tian, L., Ling, F., Wang, H., Gui, Y., \& Sun, B. (2014). Analysis of Landsat-8 OLI Imagery for Land Surface Water Mapping. Remote Sensing Letters, 5, 672-681. https://doi.org/10.1080/2150704X.2014.960606

El Bastawesy, M. (2015). Hydrological Scenarios of the Renaissance Dam in Ethiopia and Its Hydro-Environmental Impact on the Nile Downstream. Journal of Hydrologic Engineering, 20, Article ID: 04014083. https://doi.org/10.1061/(ASCE)HE.1943-5584.0001112

El Bastawesy, M., Gabr, S., \& Mohamed, I. (2015). Assessment of Hydrological Changes in the Nile River Due to the Construction of Renaissance Dam in Ethiopia. The Egyptian Journal of Remote Sensing and Space Science, 18, 65-75. https://doi.org/10.1016/j.ejrs.2014.11.001

El-Nashar, W. Y., \& Elyamany, A. H. (2018). Managing Risks of the Grand Ethiopian Renaissance Dam on Egypt. Ain Shams Engineering Journal, 9, 2383-2388. https://doi.org/10.1016/j.asej.2017.06.004

ESA (European Space Agency) (2021). Copernicus Open Access Hub. https://scihub.copernicus.eu/dhus/\#/home

Friedl, M., \& Sulla-Menashe, D. (2015). MCD12C1 MODIS/Terra+Aqua Land Cover Type Yearly L3 Global 0.05Deg CMG V006. NASA EOSDIS Land Processes DAAC.

Grace, J., San Jose, J., Meir, P., Miranda, H. S., \& Montes, R. A. (2006). Productivity and Carbon Fluxes of Tropical Savannas. Journal of Biogeography, 33, 387-400. https://doi.org/10.1111/j.1365-2699.2005.01448.x

Hassaan, M. A. (2009). Change Detection of Inland Water Bodies Using Remote Sensing Technique Case Study: Lake Maryuit, Egypt. The Arabian Journal of Geographical Information Systems, 2, 73-101.

Hassaan, M. A. (2012). Geographical Analysis of the Impacts of Shoreline Changes Using Remote Sensing and GIS Techniques. Case Study: Rosetta Nile Branch Promontory, Egypt. The Arabian Journal of Geographical Information Systems, 5, 1-24.

Irvem, A. (2011). Application of GIS to Determine Storage Volume and Surface Area of Reservoirs: The Case Study of Buyuk Karacay Dam. International Journal of Natural and Engineering Sciences, 5, 39-43.

Khairy, W. M., El-Motasem, M., Mehanna, A., \& Hefny, K. (2019). Estimation of Evaporation Losses from Water Bodies in the Sudan and Ethiopia. International Journal of Energy and Water Resources, 3, 233-246. https://doi.org/10.1007/s42108-019-00031-x

Lupia, F., Bonati, G., \& Giuseppe, P. (2018). Copernicus Sentinel-2 Imagery: How Much Data Are Available to Preform Territorial Monitoring? In XXXIX Conferenza Italiana Di Scienze Regionali (pp. 1-8). Associazione Italiana di Scienze Regionali. 
McFeeters, S. K. (1996). The use of the Normalized Difference Water Index (NDWI) in the Delineation of Open Water Features. International Journal of Remote Sensing, 17, 1425-1432. https://doi.org/10.1080/01431169608948714

Mulat, A. G., \& Moges, S. A. (2014). Assessment of the Impact of the Grand Ethiopian Renaissance Dam on the Performance of the High Aswan Dam. Journal of Water Resource and Protection, 6, 583-598. https://doi.org/10.4236/jwarp.2014.66057

Phyoe, W. W. \& Wang, F. (2019). A Review of Carbon Sink or Source Effect on Artificial Reservoirs. International Journal of Environmental Science and Technology, 16, 2161-2174. https://doi.org/10.1007/s13762-019-02237-2

Rodrigues, L. N., Sano, E. E., Steenhuis, T. S., \& Passo, D. P. (2012). Estimation of Small Reservoir Storage Capacities with Remote Sensing in the Brazilian Savannah Region. Water Resources Management, 26, 873-882. https://doi.org/10.1007/s11269-011-9941-8

Sarp, G., \& Ozcelik, M. (2017). Water Body Extraction and Change Detection Using Time Series: A Case Study of Lake Burdur, Turkey. Journal of Taibah University for Science, 11, 381-391. https://doi.org/10.1016/j.jtusci.2016.04.005

Sawunyama, T., Senzanje, A., \& Mhizha, A. (2006). Estimation of Small Reservoir Storage Capacities in Limpopo River Basin Using Geographical Information Systems (GIS) and Remotely Sensed Surface Areas: Case of Mzingwane Catchment. Physics and Chemistry of the Earth, Parts $A / B / C, 31,935-943$. https://doi.org/10.1016/j.pce.2006.08.008

Sayl, K. N., Muhammad, N. S., \& El-Shafie, A. (2017). Optimization of Area-VolumeElevation Curve Using GIS-SRTM Method for Rainwater Harvesting in Arid Areas. Environmental Earth Sciences, 76, Article No. 368. https://doi.org/10.1007/s12665-017-6699-1

Schleiss, A. J., Franca, M. J., Juez, C., \& De Cesare, G. (2016). Reservoir Sedimentation. Journal of Hydraulic Research, 54, 595-614. https://doi.org/10.1080/00221686.2016.1225320

Soussana, J. F., Tallec, T., \& Blanfort, V. (2010). Mitigating the Greenhouse Gas Balance of Ruminant Production Systems through Carbon Sequestration in Grasslands. Animal, 4, 334-350. https://doi.org/10.1017/S1751731109990784

Toochi, E. C. (2018). Carbon Sequestration: How Much Can Forestry Sequester $\mathrm{CO}_{2}$ ? Forestry Research and Engineering: International Journal, 2, 148-150. https://doi.org/10.15406/freij.2018.02.00040

USGS (United States Department of Geological Survey) (2020). Earth Explorer https://earthexplorer.usgs.gov/

Wang, Q. G., Du, Y. H., Su, Y., \& Chen, K. Q. (2012). Environmental Impact PostAssessment of Dam and Reservoir Projects: A Review. Procedia Environmental Sciences, 13, 1439-1443. https://doi.org/10.1016/j.proenv.2012.01.135

Wheeler, K. G., Jeuland, M., Hall, J. W., Zagona, E., \& Whittington, D. (2020). Understanding and Managing New Risks on the Nile with the Grand Ethiopian Renaissance Dam. Nature Communications, 11, Article No. 5222. https://doi.org/10.1038/s41467-020-19089-x

$\mathrm{Xu}$, H. (2006). Modification of Normalized Difference Water Index (NDWI) to Enhance Open Water Features in Remotely Sensed Imagery. International Journal of Remote Sensing, 27, 3025-3033. https://doi.org/10.1080/01431160600589179

$\mathrm{Xu}, \mathrm{H}$. (2007). Extraction of Urban Built-up Land Features from Landsat Imagery Using a Thematic-Oriented Index Combination Technique. Photogrammetric Engineering \& Remote Sensing, 73, 1381-1391. https://doi.org/10.14358/PERS.73.12.1381 